\title{
Health problems among the street children of Dharan municipality
}

\section{Thapa $\mathrm{K}^{1}$, Ghatane $\mathrm{S}^{2}$, Rimal $\mathrm{SP}^{3}$}

${ }^{1}$ Nursing Instructor, Charak Hospital Nursing College, Simalchaur, Pokhara, Nepal, ${ }^{2}$ Clinical Instructor, B and B Medical Institute, Gwarko, Lalitpur, Nepal, ${ }^{3}$ Intern Doctor, Kathmandu Medical College, Sinamangal, Kathmandu, Nepal

\begin{abstract}
Background: The street children, a marginalised and vulnerable population to poor health, have grown all over the world and also in our country. The continuous exposure to harsh environment and nature of their life style threatens their mental, physical, social and spiritual well being. With the increasing number the problem is also growing at an alarming proportion. It is therefore important to have baseline data on their health problems.

Objectives: This study was conducted to identify the physical health problems among the street children of Dharan Municipality, Nepal.

Materials and methods: This is a cross sectional descriptive study. Forty eight subjects were included in the study. Research instruments included an interview schedule, physical health examination performa and lab investigations (i.e. blood for haemoglobin, urine routine examination/microscopic examination, stool routine examination/ microscopic examination).

Results: Study results showed that $68.8 \%$ of the street children were between $11-15$ years of age, $95.8 \%$ were males. Out of the total subjects $81.2 \%$ were found to be rag pickers. Research findings reveal that $100 \%$ of the subjects had at least one or more health problems. The study revealed that majority $87.5 \%$ had the habit of cigarette smoking, $50 \%$ had habit of consuming alcohol and $72.9 \%$ had the habit of taking drug. Dendrite (glue sniffing) was the only drug used by the respondents in this study. The most common health problems were head lice infestation $(81.2 \%)$, headache $(66.7 \%)$, cut injury $(60.4 \%)$, common cold $(52.1 \%)$, dental caries $(52 \%)$, burning micturation $(47.9 \%)$, cough $(47.9 \%)$, underweight (43.8\%), abdominal pain (39.6\%), tinnitus (37.55\%), gum bleeding (33.3\%), joint pain (31.2\%), eye inflammation (25\%), leg cramps (25\%), palpable lymph nodes (25\%), chest pain (18.8\%), skin lesions (16.7\%), abnormal vision $(8.3 \%)$.

Conclusion: Most of the diseases were due to poor health habits. It was found that the nature of work, their life styles and the different types of behaviour they adapt finally lead them to many health problems. The health problem can be prevented, if an integrated program that involves all the issues are developed and implemented.
\end{abstract}

Key words: Street children, health problems, Dharan.

$\mathrm{T}$ he problem of street children is growing at an alarming proportion worldwide. They are the reflection of growing social tragedy in the world. "Street children" is not a functional term in itself because it is impossible to define it clearly. The meaning and definition of street children is contested among academics, policy makers, practitioners, politicians and the general public. Individuals and groups have their own preferred definition ${ }^{1}$.

A widely accepted set of definition, commonly attributed to UNICEF defines street children into two main categories ${ }^{2}$.

1. Children on the street are those engaged in some kind of economic activity ranging from begging to vending. Most go home at the end of the day and contribute their earnings to their family. They may be attending school and retain a sense of belonging of a family. Because of the economic fragility of the family, those children adapt for a permanent life on the street.

2. Children of the street actually live on the street (or outside of a normal family environment). Family ties may exist but are tenuous and are maintained only casually or occasionally. They work, live and sleep in the streets.

Correspondence

Dr. Surya P. Rimal

Intern Doctor

Kathmandu Medical College

Sinamangal, Nepal

E-mail: sprimal@hotmail.com 
Street children, a dynamic population, shifting as opportunities arise, moving in and out of the other designated categories of children. Street children are not usually counted, not subject to census so their numbers are not known. Different organisations produce local estimates of the total number of street children in different regions of the world ${ }^{1}$. According to UNICEF, the latest estimates put the numbers of these children as high as 100 million. And even more recently the figure almost runs certainly into ten of millions across the world ${ }^{2}$. In Nepal the total estimated number is 40,000 . There are estimated to be 800 to 1200 children on the street in the Kathmandu valley ${ }^{2}$. According to the survey done by Underprivileged Children Association (UPCA), a NGO working for the street children in Dharan the estimated number of the street children was around 50.

The increasing phenomenon of street children have been linked with several related factors like economic recession, poverty, unemployment, rural to urban migration, war, political instability, natural calamities, family breakdown and violence including physical, emotional and sexual abuse ${ }^{3}$.

Street children constitute a marginalised group. They do not have relationship with major institutions of childhood such as family, education and health; which society considers the most essential. The continuous exposure to the harsh environment and the nature of their life style threatens their physical, mental, social and spiritual wellbeing ${ }^{4}$.

There are no official statistics regarding the general health of the street children. Limited literature available till date reveals the prevalence of a wide range of physical health problems among them. Substance Abuse which is the most common behavioural problems also jeopardises the child's physical health ${ }^{5}$.

They are among the most deprived and they usually have no access to healthcare and education. All these conditions have led to precipitation of various communicable and non communicable diseases. If such trend increases ahead without any preventive and control measure this will be serious threat to the society in the future. Health is vital to all and should be given the first priority. A child in poor health cannot be motivated to be involved in other programs developed for him/her unless his/her health is addressed and s/he is provided an easy access to health services.

\section{Objectives}

The objectives of the study were as follows.

To identify the physical problems of the street children in Dharan Municipality.
To identify the treatment sought out by the street children

\section{Materials and methods}

This is a cross sectional descriptive study. Forty eight subjects comprised the sample size of the study. Snowball sampling method was adopted.

\section{Research instrument included the following:}

\section{Interview schedule}

An interview consisting of 34-item semi-structured questionnaire was used for data collection. The instrument consisted of demographic data, information regarding health habits, health history. Physical health assessment Performa:

A physical examination comprising of head to toe examination was carried out in all the subjects. It also comprised the anthropometric measurements and assessment of vital signs. It also included the health problems perceived by the subjects.

\section{Laboratory Investigations}

The laboratory tests performed were blood for haemoglobin status, urine routine and microscopic examination and stool routine and microscopic examination. The tests were performed at the time of data collection only and the tests were conducted by the central laboratory in BP Koirala Institute of Health Sciences, Dharan.

In the study the normal range for Body Mass Index (BMI) was taken from CDC 2000 standards. Blood pressure was monitored on both the arms of those subjects who were found with increased blood pressure on one arm at first time. The children who were found with increased blood pressure could not be followed up as it was very difficult to trace them and thus was included as the limitation of the study.

Descriptive statistics was used for the purpose of analysis using SPSS package.

\section{Result}

\section{Demographic Characteristics}

Out of total subjects, 46(95.8\%) were male and $33(68.8 \%)$ belonged to $11-15$ years of age. In the study $37(77.1 \%)$ were found to be the children on the street and remaining $11(22.9 \%)$ were the children of the street. In the study, 19 (39.6\%) were found to be dalit children. Regarding occupation, majority 39 (81.2\%) were found to be rag pickers and daily income ranged from Rs. 50-100 in 20 (41.7\%) of the subjects while 16 $(33.3 \%)$ earned more than Rs.100. The first priority of spending money was food in $45(93.8 \%)$ followed by 
substance use in $39(81.2 \%)$. During the time of study, $39(81.2 \%)$ were not attending school. Regarding past education, 33( $84.6 \%$ ) had attended primary school. The highest number of children i.e. $27(56.3 \%)$ came to street due to peer influence while $22(45.8 \%)$ came for earning.

\section{Health habits}

Majority of the subjects 29 of them $(60.4 \%)$ took bath rarely i.e. usually not before one month and $32(66.7 \%)$ did not have the habit of brushing teeth. Majority 42 $(87.5 \%)$ of them wore slippers all the time. Regarding the eating habits, most of them $29(60.4 \%)$ consumed meal three times a day and $23(47.9 \%)$ reported consuming meat multiple times a week. All of them i.e. $48(100 \%)$ of them were found to be non vegetarian. Majority of subjects 36 of them (75\%) took food at their house while $22(45.8 \%)$ of them consumed their food in hotels.
Table 3 depicts the various measures adopted by the street children when they had illness. Many (17.8\%) of them took self medications for worm infestation while there was no treatment sought out for other GI problems (48.9\%) that includes abdominal pain, diarrhoea, vomiting, heart burn etc. Others include burn, fall injury, accidents, dog bite etc for which only $13.3 \%$ had sought medical help.

Of the total subjects $43.8 \%$ were found to be underweight, $16.7 \%$ had hypertension, $20.8 \%$ had tachypneoa, $8.3 \%$ had fever and $6.2 \%$ had tachycardia. The common health problems identified were dry and scaly skin (91.7\%), stained teeth $(91.7 \%)$, head lice infestation $(81.2 \%)$, cut injury (60.4\%), dental caries (52\%), nasal discharge $(50 \%)$, sore on lips $(31.2 \%)$, eye inflammation $(25 \%)$, palpable lymphnodes $(25 \%)$, eye discharge $(18.8 \%)$, head injury (18.8\%), skin lesions (16.7\%).

Table 1: Prevalence of substance use

$(n=44)$

\begin{tabular}{|l|l|}
\hline Type of Substance & Prevalence (\%) \\
\hline Cigarette smoking & 87.5 \\
\hline Tobacco chewing & 37.5 \\
\hline Alcoholism & 50 \\
\hline Drug abuse & 72.9 \\
\hline
\end{tabular}

Table 2: Health Problems Experienced in Last Six Month

$(n=48)$

\begin{tabular}{|l|c|c|c|}
\hline \multicolumn{1}{|c|}{ Characteristics } & Category & Frequency & Percentage \\
\hline \multirow{2}{*}{$\begin{array}{l}\text { Health Problems in last 6 } \\
\text { months }\end{array}$} & Yes & 45 & 93.8 \\
\cline { 2 - 4 } & No & 3 & 6.2 \\
\hline
\end{tabular}

$(n=45)$

\begin{tabular}{|l|l|c|c|}
\hline \multicolumn{1}{|c|}{ Characteristics } & \multicolumn{1}{|c|}{ Category } & Frequency & Percentage \\
\hline \multirow{5}{*}{ If yes type of disease } & Gastrointestinal problems & 41 & 91.1 \\
\cline { 2 - 4 } & Skin problems & 13 & 28.9 \\
\cline { 2 - 4 } & Others(burn, dog bite, fall injury) & 12 & 22.7 \\
\cline { 2 - 4 } & Cut injury & 10 & 22.2 \\
\cline { 2 - 4 } & Respiratory problems & 10 & 11.1 \\
\cline { 2 - 4 } & Fever & 5 & 8.9 \\
\cline { 2 - 4 } & Problems related to ear and nose & 4 & 4.4 \\
\cline { 2 - 4 } & Headache & 2 & \\
\cline { 2 - 4 } & & & \\
\hline
\end{tabular}

Note: Many subjects had multiple health problems 
Table 3: History of Health Problems and Different Measures Adopted

$(n=45)$

\begin{tabular}{|l|c|c|c|c|c|c|c|c|}
\hline \multirow{2}{*}{ Health problems } & \multicolumn{2}{|c|}{ Clinic/ Hospital } & \multicolumn{2}{c|}{ Self medications } & \multicolumn{2}{|c|}{ UPCA } & \multicolumn{2}{c|}{ No Treatment } \\
\cline { 2 - 10 } & $\mathbf{f}$ & $\mathbf{\%}$ & $\mathbf{f}$ & $\mathbf{\%}$ & $\mathbf{f}$ & $\mathbf{\%}$ & $\mathbf{f}$ & \% \\
\hline Fever & 3 & 6.7 & 1 & 2.2 & - & - & 1 & 2.2 \\
\hline Headache & - & - & - & - & - & - & 2 & 4.4 \\
\hline Respiratory problems & 5 & 11.1 & - & - & - & - & 5 & 11.1 \\
\hline Skin problems & 4 & 8.9 & 1 & 2.2 & - & - & 8 & 17.8 \\
\hline Worm infestation & - & - & 8 & 17.8 & 3 & 6.7 & 2 & 4.4 \\
\hline Other GI problems & 1 & 2.2 & 3 & 6.7 & 2 & 4.4 & 22 & 48.9 \\
\hline $\begin{array}{l}\text { Problems related to ear and } \\
\text { nose }\end{array}$ & 1 & 2.2 & 1 & 2.2 & 1 & 2.2 & & 2 \\
\hline Cut injury & 4 & 8.9 & 1 & 2.2 & 2 & 4.4 & 3 & 6.2 \\
\hline Others & 6 & 13.3 & 2 & 4.4 & - & - & 4 & 8.9 \\
\hline
\end{tabular}

Note: Many subjects had multiple health problems

Table 4: Distribution of Perceived Health Problems among the Street children

$(n=48)$

\begin{tabular}{|c|c|c|c|}
\hline Characteristics & Category & Frequency & Percentage \\
\hline Hair & Hair fall & 14 & 29.1 \\
\hline \multirow[b]{2}{*}{ Eye } & Difficulty in seeing at night & 8 & 16.7 \\
\hline & Eye pain & 14 & 29.1 \\
\hline \multirow{3}{*}{ Ear } & Ear ache & 8 & 16.7 \\
\hline & Tinnitus & 18 & 37.5 \\
\hline & Hearing problem & 12 & 25 \\
\hline \multirow{3}{*}{ Nose } & Injury & 2 & 4.1 \\
\hline & Bleeding & 11 & 22.9 \\
\hline & Common cold & 25 & 52.1 \\
\hline Teeth & Toothache & 22 & 45.8 \\
\hline Gum & Bleeding & 16 & 33.3 \\
\hline \multirow{2}{*}{ Throat and Neck } & Sore throat & 7 & 14.6 \\
\hline & Difficulty in swallowing & 7 & 14.6 \\
\hline Skin & Itching & 27 & 56.2 \\
\hline Urinary tract & Burning micturation & 23 & 47.9 \\
\hline \multirow{2}{*}{ Reproductive tract } & Discharge & 3 & 6.2 \\
\hline & Lesion & 4 & 8.3 \\
\hline \multirow{2}{*}{ Extremities } & Joint pain & 15 & 31.2 \\
\hline & Cramps & 12 & 25 \\
\hline
\end{tabular}

Note: Many subjects had multiple health problems 
Table 5: Perceived health related problems $(n=48)$

\begin{tabular}{|l|l|c|}
\hline System & Illness & Prevalence \\
\hline \multirow{5}{*}{ Head related } & Headache & 66.7 \\
\cline { 2 - 3 } & Injury & 18.8 \\
\cline { 2 - 3 } & Dizziness & 39.6 \\
\hline \multirow{5}{*}{ Gespiratory related } & Cough & 47.9 \\
\cline { 2 - 3 } & Difficulty in breathing & 12.5 \\
\cline { 2 - 3 } & Chest pain & 18.8 \\
\hline \multirow{5}{*}{} & Anorexia & 16.7 \\
\cline { 2 - 3 } & Nausea/vomiting & 16.7 \\
\cline { 2 - 3 } & Diarrhoea & 12.5 \\
\cline { 2 - 3 } & Constipation & 31.2 \\
\cline { 2 - 3 } & Heartburn & 25 \\
\cline { 2 - 3 } & Abdominal pain & 39.6 \\
\cline { 2 - 3 } & Blood/mucus in stool & 14.6 \\
\cline { 2 - 3 } & Pruritus periani & 10.4 \\
\cline { 2 - 3 } & Passing of worms & 8.3 \\
\hline
\end{tabular}

Table 6: Lab Investigations $(n=48)$

\begin{tabular}{|c|l|c|c|}
\hline Characteristics & \multicolumn{1}{|c|}{ Category } & Frequency & Percentage \\
\hline \multirow{5}{*}{ Urineanalysis } & Normal & 44 & 91.6 \\
& Bacteria & 1 & 2.1 \\
& Caoxalate & 2 & 4.2 \\
& Uricacid & 1 & 89.1 \\
\hline \multirow{5}{*}{ Stoolanalysis } & Normal & 43 & 4.2 \\
& Ascarislumbricoids & 2 & 4.2 \\
\hline Hemoglobin & Giardialamblia & 2 & 2.1 \\
\hline
\end{tabular}

\section{Discussion}

Street children are of widely different ages ${ }^{1}$. This research finding showed that $68.8 \%$ of the subjects were between 11-15 years of age. This does correspond to the research finding by Child protection centre and services (CPCS) in Kathmandu in which among 430 subjects $67 \%$ were between the ages of 12-16 years $^{8}$. The probable reason is because this is the phase when children can see themselves as old enough to work and earn and hence are more likely to leave home or sent out to work.

Both males and females suffer mostly from financial hardships that push them out of their homes. This study showed that majority $(95.8 \%)$ were males which corresponds to the research finding by Child protection centre and services ${ }^{8}$ in which $99 \%$ of the sample were male. The female subjects were least in comparison to male, this may be because many girls work in houses as domestic servant and street life is more dangerous for them as they are more likely to be sexually abused than boys.

Street children seldom get job of good kind. Majority scavenge or pick through garbage for scraps and sell it using it as a means of earning. Majority of the subjects i.e. $81.2 \%$ were found to be rag pickers, $14.6 \%$ street vendor and $4.2 \%$ work in hotel. This does correspond to the research finding by $\mathrm{CPCS}^{8}$ in which out of 430 respondents, $49 \%$ were found to be rag pickers.

Working in the street environment poses many hazards and risks to children on the street leading to numerous health problems. Lack of access to bathing and toilet facilities and medical care further accentuate their poor 
health condition. This study depicts that majority had problems in hair among which $81.2 \%$ had head lice/nits. This finding corresponds with the study done by $\mathrm{CPCS}^{8}$ which revealed $74 \%$ of the respondents had head lice infestation. An article by Scott Pemberton in Kiwanis magazine, Ghana ${ }^{9}$ reported lice in $48 \%$ of the street children which is less than the result of our study.

Street children who use rag picking as source of earnings, work long hours scavenging for any profitable waste through out the day in hot climate, so climatic condition can be a cause for the headache. In the present study, majority $66.7 \%$ reported headache. This contradicts with the study report in $Z_{\text {ambia }}{ }^{10}$ which depicts that only $15.3 \%$ of the street children had headache. A study conducted in 2 cities of Ukraine ${ }^{5}$ depicted headache (55\% Kyiv and $40 \%$ Odesa) which is also less than the finding of this study. Similarly a study in Banglore ${ }^{11}$ revealed headache in $41 \%$ of the subjects, which is also less than the result of this study.

Among the 48 subjects enrolled in the study, the problems identified in eyes were eye inflammation (25\%), yellowish sclera $(4.1 \%)$, pale conjunctiva (4.1\%), eye discharge (18.8\%) and abnormal vision of any one or both eyes in $8.3 \%$. The problems in eye reported by the subjects were difficulty in seeing at night (16.7\%) and eye pain (29.1\%).Literature is devoid of exploration of eye problems, however, the result of this study highly contradicts with the report of the study conducted in $Z_{\text {ambia }}{ }^{10}$ which depicts only $0.7 \%$ of subjects experiencing eye problems. The contradictory result may be because this is only the subjective data experienced by the subjects participating in the study of Zambia. Moreover the research itself stresses the fact that accepting the diagnostic skills of respondents are probably very limited, this figure needs to be treated with concern and should be used as a basis for further investigation $^{10}$.

Regarding the problems related to nose, the reported problems were $52.1 \%$ common cold, $22.9 \%$ nasal bleeding and nasal discharge was found in $50 \%$ of the subjects. Common cold was found more probably because the data collection time was in winter, when the street children were more exposed to the cold environment and they did not have warm clothes to wear. The result of the study highly contradicts with the study conducted in Zambia ${ }^{10}$, which depicted only $0.4 \%$ ear infections, $0.9 \%$ cold and flu and $0.4 \%$ nasal bleed. The study in Awassa ${ }^{12}$, also found that ear and nose disease as minor.

In the present study, $45.8 \%$ reported toothache. This study result contradicts with the study conducted in Awassa $^{12}$, where toothache was considered as minor health problem. A study in Banglore ${ }^{11}$ reported $27 \%$ having toothache which is less than the result of our study. Tooth ache was found more because in this study the results showed that $66.7 \%$ did not have the habit of brushing teeth.

Many studies show that respiratory infections are the major health problems experienced by street children. In this study, $14.6 \%$ reported sore throat and same percentage reported difficulty in swallowing. The other problems reported were $47.9 \%$ cough, $47.7 \%$ sputum, $18.8 \%$ chest pain and $12.5 \%$ difficulty in breathing. The habit of substance use (87.5\% smoking cigarettes, $37.5 \%$ chewing tobacco, $72.9 \%$ taking drugs) may be one of the reason that lead majority to experience respiratory problem. As the data was collected in winter, exposure to cold environment and lack of warm clothes might have aggravated the respiratory problems. This finding is supported by the study conducted in Awassa ${ }^{12}$, in which respiratory tract illness $(31.6 \%)$ was the major disease reported by the street children. The study result is supported by study conducted in Banglore ${ }^{11}$, in which common complaints were cough, breathing problem and chest pain in $56 \%$ of the subjects. The study result is also consistent to the study report conducted in Ukraine $^{5}$ where the most common problems were respiratory problems (56\%Kyiv and $50 \%$ Odesa). The study result is also supported by study conducted in Kenya $^{13}$ in which most common symptoms was cough $28.9 \%$ while frequent diagnosis was upper respiratory tract infection $(12.1 \%)$ though percentage is less than result of our study.

Street children are exposed to contaminants and bacteria while scavenging the garbage and so majority had problems related to skin. The skin problems identified were $91.7 \%$ dry and scaly skin, $60.4 \%$ cut injury and $16.7 \%$ had skin lesions. This finding is supported by the study in Kenya ${ }^{13}$ in which skin disease (50.9\%) fall under leading disease of the street children. The study conducted by $\mathrm{CPCS}^{8}$ in Kathmandu revealed $22 \%$ of the respondents having skin infection which is less than the result of our study. Another study conducted in 2 cities of Ukraine ${ }^{5}$ showed that 41\% Kyiv and 20\% in Odessa had bodily injuries, traumas and bruises. The study conducted in Banglore ${ }^{11}$ revealed that $26 \%$ respondents had skin problems which are less than the finding of our study.

Street children consume their food as available and where accessible and the food they take is not usually hygienic resulting in Gastrointestinal problems. The study result showed that among the total respondents, $39.6 \%$ reported abdominal pain, $16.7 \%$ complained of nausea \& vomiting and $12.5 \%$ complained of diarrhoea. This finding is supported by the study conducted in 2 
cities of Ukraine ${ }^{5}$ which revealed abdominal pain in majority of the respondents i.e. 44\% in Kyiv and 37\% in Odessa. Another study conducted in Banglore ${ }^{11}$ revealed $29 \%$ of the respondents had stomach problems. A study conducted in Awassa ${ }^{12}$ showed that $4.3 \%$ of the total subjects had diarrheal disease which is less than the result of our study.

Street children are found to be under weight for age despite bigger earnings and spending majority of their earnings on food. This is due to the acquisition of poor eating habits (usually noodles and other food lacking the essential nutrients). Majority of them consume noodles and other junk food in breakfast and lunch while rice with vegetables comprised their dinner. The finding of this study revealed that $43.8 \%$ were under weight for age which corresponds with the study in Kenya ${ }^{13}$ where malnutrition is high with $31.1 \%$ and $41.9 \%$ of children being stunted and under weight respectively. A study conducted in Manila ${ }^{15}$ revealed that $45.7 \%$ were underweight for age which corresponds with the result of our study. An article written by Scott Pemberton in Kiwanis magazine, Ghana ${ }^{9}$ reported malnutrition in $83 \%$ of the subjects which is very high than the result of this study.

Stool test for parasite infestation in the present study revealed that out of the total subjects, only $8.4 \%$ had parasitic infestation. This study contradicts with many other studies, where worm infestation is a common health problem among them. The study conducted by $\mathrm{CPCS}^{8}$ in Kathmandu revealed $18 \%$ of the respondents had worm infestations. An article by Scott Pemberton in Kiwanis magazine, Ghana ${ }^{9}$ revealed $92 \%$ having parasitic infestation. This contradictory result may be because $28.9 \%$ of the street children had reported worm infestation in last six month and out of them $17.8 \%$ had self medication and $6.7 \%$ had sought help from Underprivileged children association. Moreover, UPCA had also done mass de-worming to the street children a month prior to the period of data collection.

The study result revealed $6.2 \%$ being anaemic. This finding contradicts with the study in Cairo $^{16}$ which revealed $73 \%$ of subjects had low level of haemoglobin. An article by Scott Pemberton in Kiwanis magazine, Ghana $^{9}$ reported anaemia in $78 \%$ of the street children. Anaemia is prevalent in these studies as compared to the result of our study Meat is a major source of iron and $47.9 \%$ consumed meat multiple times a week, this may be the reason for the low percentage of anaemia among the street children in this study.

In the present study, out of the 48 subjects, $4.2 \%$ subjects had calcium oxalate in urine. A study in Cairo ${ }^{16}$ revealed $30 \%$ had high level of salts in their urine. This finding contradicts with the result of our study.
Street children being socially marginalised cannot afford most health services, thus receive no treatment for many illnesses they suffer and self medication is preferred. In this study, $35.6 \%$ had attended clinics or hospitals, and $26.7 \%$ had self medications, $13.3 \%$ sought help from UPCA, the organisation working for the street children while majority $66.7 \%$ had no treatment for the health problems they experienced in last six months. Majority of the respondents usually took the medicines from the clinics for worm infestations $(17.8 \%)$ while there was no treatment sought out for other GI problems (48.9\%). Report of the study conducted by CPCS $(2007)^{8}$ revealed that $60 \%$ of the respondents reported having been very ill, while $50 \%$ had visited doctor or a hospital and $9 \%$ of the respondents had been refused treatment by a medical authority. Another study conducted in 6 cities of Nepal revealed that about $62 \%$ of rag pickers $(2001)^{17}$ interviewed had experienced sickness as a result of their occupation among them $73.1 \%$ consulted doctor for treatment. A qualitative study conducted in Pakistan $(2005)^{18}$ revealed that more than $34 \%$ of street children got treatment from government hospital, when they have any major illness. More than 7\% got treatment in private centers while $4.8 \%$ children used self medication.

\section{Conclusion}

The most common health problems were due to poor health habits. It was found that the nature of work, their life styles and the different types of behaviours they adapt finally lead them to many health problems. These health problems can be prevented if an integrated program that involves all the issues are developed and implemented.

Children are coming to street not because there is a demand but back at home they have more complex factors pushing them out of family, out of community and out of school rather than pulling them to street. So, in order to address the street children's needs we have to develop integrated programme that involve all the factors. Although street children are earning, their life style encourage them to spend all they have and they do not have future in what they do as an earning and which jeopardises their health. So, interventions need to be made to encourage children to access developmental services such as education, recreation and vocational training.

\section{Implications}

1. This study would strengthen knowledge regarding the health issues faced by the street children.

2. The present study undertaken showed overview of reported and identified illness occurring in the street children which can be utilised for planning and policy development in regard for street children. 
3. The findings of study will help to establish evidence to advocate the need for health of street children and draw attention of government, NGOs/INGOs to provide sustainable health care facilities.

\section{Recommendations}

1. Similar study can be conducted in other big cities of Nepal like Kathmandu, Pokhara, and Butwal where large population and diversity of street children from various parts of the country can be found.

2. Study can also be conducted to assess the psychological problems of the same group.

3. Health interventions focusing on the prevention and promotion of the street children are first and foremost necessities for which provision of mobile health services and Street children help line can be established to meet the health needs of the children.

4. Organisation working for street children should come together at the national level through networking with the objective to address the problems of street children.

5. Income generating program for the family's of street children and vocational training for street children would be a measure for improving their outcomes. It would also enable them to make out their own living and provide a safe and more profitable ways of earning money.

\section{References}

1. West A. At the margins: Street children in Asia and the Pacific. Asian Development Bank [homepage in Internet].2003. [cited 2007 Oct 8]; Available from:http://.streetchildren.org.uk/ reports/AWest $\% 20$ street $\% 20$ childrenfinal.pdf.

2. Street children. Wikipedia, the free encyclopedia [homepage in Internet]. 2007 [cited 2007 Oct 8]; Available from: http://en.wikipedia.org/ wiki/streetchildren

3. D’Souza B, Castelino, Madangopal D. A demographic profile of street children in Mumbai [Homepage in Internet]. 2007 [cited 2007 Sep 18]; Available from:http://www. shelterdonbosco.org/demographicprofile.pdf.

4. Working with the Street Children. World Health Organization [Homepgage in Internet]. 2000 [cited 2007 Sep 20]; Available from: http:// www.unodc.org/pdf/youthnet/ who street children introduction.pdf

5. UNICEF, Ukraine [homepage on the Internet]. 2006 [cited on 27th September 2007]. Children and young people living or working on the streets: The missing face of the HIV Epedimic in Ukraine. Available from: http://www.unicef. org/ukraine/media_7466.html

6. Ghai OP.Gupta P, Paul VK. Essential Peadiatrics. 6th edition. India: CBS; 2005.

7. Myung PK. Pediatric Cardiology for Practioners.4th edition. Texas: Mosby; 2004.

8. Christophe JR. Study, approaches and comments on the daily life of the street-based children of the Nepalese capital, Kathmandu: CPCS; 2007.

9. Pemberton S. Saving the street Children. Kiwanis Magazine. Indianapolis: Kiwanis International; 2007.p. 1-6.

10. Lukas M, Derrick E, Lukas M et al. Report on survey and analysis of the situation of the situation of street children in Zambia. Zambia: Ministry of Community Development and Social Services; 2006.

11. Benegal V, Bhusan K, Seshadri Sr, Karott M. Drug abuse among street children in Banglore. India: National Institute of Mental Health and Neuroscience, Bangalore Forum for street and working children; 1998.

12. Sorsa S, Kidanemariam T, Erosie L. Health problems of street children and women in Awassa, Southern Ethiopia. Ethiop J Health Dev.2002;16(2):129-37.

13. Ayaya SO, Esamai FO. Health Problems of the Street Children in Eldoret, Kenya. East Africa Med Journal. 2001; 78(12): 624-9.

14. Iqbal F. KABPS study for street children in Karachi. Pakistan: Pakistan Voluntary Health and Nutrition Association (PAVHNA); 2004.

15. DOST [homepage on the internet]. 2007[Cited on 14th May, 2008]. The Nutritional Status of Street children: Why some are nutritionally well-off or worst off? Available from: http:// www1.fnri.dost.gov.ph/htm/streetchildren.htm.

16. Eltahalwy EM, Schawki MM, Ghobashi MM, AUC Social Research Center. An Evaluation of the Health condition of street children in Cairo. Public Health and Human rights, APHA 134th Annual Meeting and Exposition; November, 2006.

17. KC Balkumar, Gurung Y, Adhikari K, Suvedi G. Situation of Child Ragpickers: A Rapid Assessement. Geneva: ILO/IPEC; 2001.

18. Tufail P. Report on Situational Analysis of Street Children Education for All Policy Review and Best Practices Studies on Basic NFE for Children living and Working on the streets. Pakistan: Amal Human Development Network, UNESCO; 2005. 